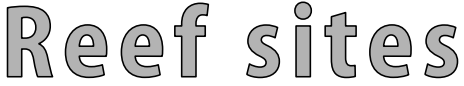

\section{A phase shift from macroalgal to coral dominance in the Mediterranean}
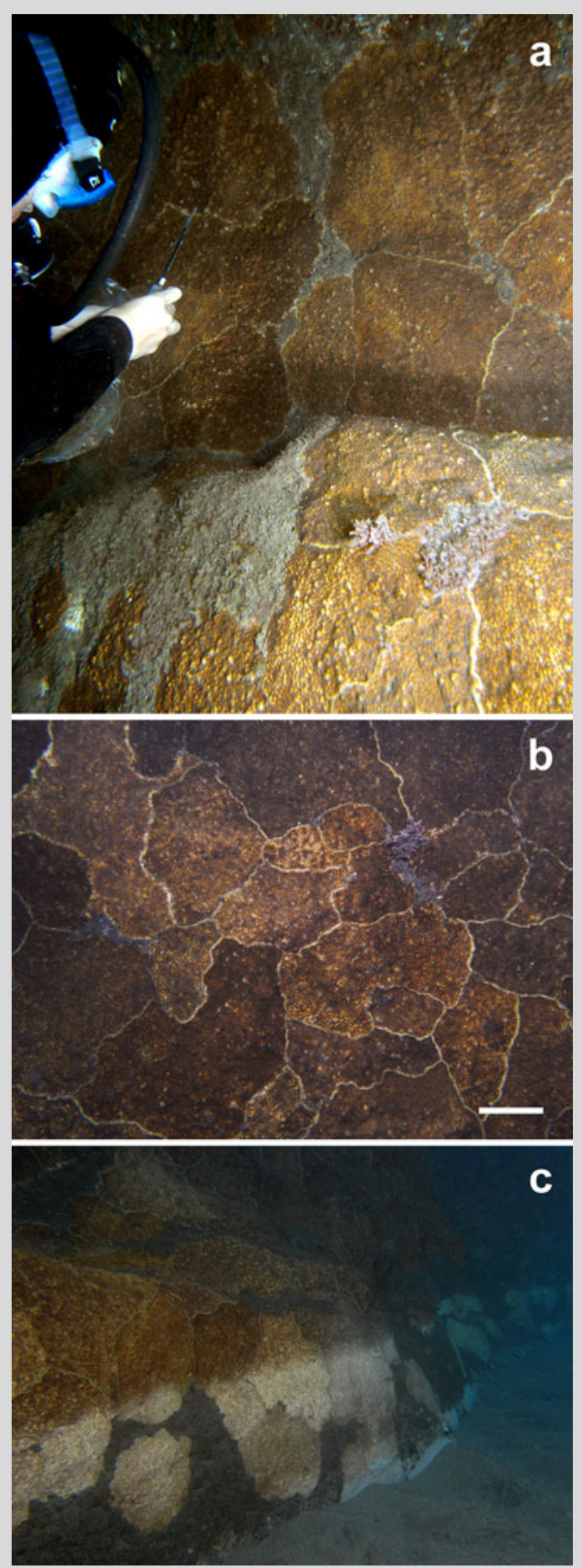

Fig. 1 a, b Community dominated by Oculina patagonica in the western Mediterranean. Scale bar $20 \mathrm{~cm}$. c The shallow water community was severely affected by sand scouring
Macroalgae dominate Mediterranean shallow water assemblages, whilst corals are extremely rare. Oculina patagonica is a zooxanthellate coral that was first recorded in the Mediterranean in 1966 and is thought to originate in the SW Atlantic. Although it is spreading in the Mediterranean, it has never been observed as main component of a natural community. In 2009, $O$. patagonica was found to be abundant in shallow water (0-3-m depth) at Torre Pirulico in SE Spain $\left(37^{\circ} 4^{\prime} 70^{\prime \prime} \mathrm{N}, 1^{\circ} 50^{\prime} 59^{\prime \prime} \mathrm{W}\right)$. Based on 25 random $1-\mathrm{m}^{2}$ plots, the mean density was $24( \pm 2 \mathrm{SE})$ colonies $\mathrm{m}^{-2}$, covering $55 \pm 5 \%$ of the $750 \mathrm{~m}^{2}$ study area (Fig. 1a, b). Coral colonies ranged from 0.07 to $3578 \mathrm{~cm}^{2}\left(\right.$ mean $\left.=229 \pm 11 \mathrm{~cm}^{2}, n=603\right)$ and their size distribution was positively skewed with $37.5 \%$ colonies $<100 \mathrm{~cm}^{2}$, indicating that strong recruitment was the main cause of the species' high abundance. Other components of the benthic community included turf algae (36.6\%), erect algae $(7.3 \%)$, sponges $(0.9 \%)$, calcareous-encrusting macroalgae and bare rock $(0.2 \%)\left(n=30\right.$ random $0.25-\mathrm{m}^{2}$ quadrats). Sea urchins were absent and physical disturbance from sand scouring (Fig. 1c) was the main source of open space for $O$. patagonica to colonise.

Whilst high cover of $O$. patagonica has been recorded on artificial habitats, cover on natural substrata is generally sparse $(<15 \%$, Fine et al. 2001; Sartoretto et al. 2008; Coma et al. 2011). It is unclear how O. patagonica outcompetes algae and other invertebrates. Densities at Torre Pirulico are the highest ever reported. This is a coral community dominated by $O$. patagonica.

Our finding of a persistent phase shift from macroalgal to coral dominance in the Mediterranean contrasts with the reported trend in many coral reef ecosystems. Macroalgae are important primary producers in temperate coastal ecosystems and this change in the dominant trophic group may affect ecosystem function.

Acknowledgments We are grateful to Laura Navarro for field assistance. Support has been provided by MCI project CGL2010-18466, CoCoNet (FP7 GrantAgreement:287844) and the Marine-Biogeochemistry and Global-Change-Research group from Generalitat de Catalunya.

\section{References}

Coma R, Serrano E, Linares C, Ribes M, Díaz D, Ballesteros E (2011) Sea urchins predation facilitates coral invasion in a Marine Reserve. PLoS ONE 6:e22017

Fine M, Zibrowius H, Loya Y (2001) Oculina patagonica: a non-lessepsian scleractinian coral invading the Mediterranean Sea. Mar Biol 138:1195-1203

Sartoretto S, Harmelin JG, Bachet F, Bejaoui N, Lebrun O, Zibrowius H (2008) The alien coral Oculina patagonica De Angelis, 1908 (Cnidaria, Scleractinia) in Algeria and Tunisia. Aquat Invasions 3:173-180

\section{E. Serrano $(\bowtie) \cdot$ R. Coma}

Centre d'Estudis Avançats Blanes (CEAB-CSIC), Accés Sant Francesc 14, 17300 Blanes, Spain

e-mail: eserrano@ceab.csic.es

\section{E. Serrano $\cdot$ M. Ribes}

Institut Ciències Mar (ICM-CSIC), Passeig Marítim Barceloneta 37-49, 08003 Barcelona, Spain 